\title{
The Value of Partial HPV Genotyping After Conization of Cervical Dysplasias
}

\section{Nutzen der partiellen HPV-Genotypisierung nach Konisation zervikaler Dysplasien}

Authors

Kristin Friebe, Rüdiger Klapdor, Peter Hillemanns, Matthias Jentschke

Affiliation

Klinik für Frauenheilkunde und Geburtshilfe,

Medizinische Hochschule Hannover, Hannover, Germany

Key words

conization, human papilloma virus, cervical intraepithelial neoplasia, HPV-genotyping

Schlüsselwörter

Konisation, humanes Papillomvirus, zervikale intraepitheliale Neoplasie, HPV-Genotypisierung

received 12.3.2017

revised 31.5.2017

accepted 29.6.2017

Bibliography

DOI https://doi.org/10.1055/s-0043-115395

Geburtsh Frauenheilk 2017; 77: 887-893 @ Georg Thieme

Verlag KG Stuttgart · New York | ISSN 0016-5751

Correspondence

Dr. med. Matthias Jentschke

Klinik für Frauenheilkunde und Geburtshilfe,

Medizinische Hochschule Hannover

Carl-Neuberg-Straße 1, 30625 Hannover, Germany

Jentschke.Matthias@mh-hannover.de

$\theta$

Deutsche Version unter:

https://doi.org/10.1055/s-0043-115395

\section{ABSTRACT}

Introduction In this retrospective study partial genotyping of human papilloma viruses (HPV) using the Abbott RealTime HighRisk HPV Test (RealTime) was compared with simple HPV detection (Qiagen Hybrid Capture 2 Test; hc2) for recurrence prediction at the first follow-up examination after conization of cervical intraepithelial neoplasia (CIN).

Methods 144 women who had undergone conization for CIN between January 2007 and December 2013 were included. HPV status was determined preoperatively and at first follow- up using hc2 in 103 women and RealTime in 41 women. Recurrent or persistent CIN was assumed when CIN2+ was confirmed histologically or on comparable cytology findings.

Results Of the 144 women with complete data 12 (8.3\%) had a recurrence after conization. HPV persistence at follow-up correlated significantly with recurrence (hc2: $p=0.003$; RealTime: $p=0.003$ ) and both sensitivity and specificity were high (hc2 $=100$ and $78.4 \%$ respectively; RealTime $=75.0$ and 83.9\%). Whereas isolated HPV testing had a relatively low positive predictive value for recurrence (hc2 16\%; RealTime $54.5 \%$ ), this rose to $80 \%$ with HPV 16 detection at follow-up. Conclusion At follow-up after conization of CIN the combination of high risk HPV detection and partial genotyping of HPV 16 constitutes excellent diagnostic criteria for recurrence/persistence of CIN.

\section{ZUSAMMENFASSUNG}

Einleitung In dieser retrospektiven Studie wurde die partielle Genotypisierung humaner Papillomviren (HPV) mithilfe des Abbott RealTime HighRisk HPV Tests (RealTime) verglichen mit dem einfachen HPV-Nachweis (Qiagen Hybrid Capture 2 Test; hc2) zur Vorhersage eines Rezidivs in der 1. Followup-Untersuchung nach Konisation bei zervikaler intraepithelialer Neoplasie (CIN).

Methodik Es wurden 144 Frauen eingeschlossen, die im Zeitraum von Januar 2007 bis Dezember 2013 aufgrund einer CIN einer Konisation unterzogen wurden. Der HPV-Status wurde präoperativ, sowie zur 1. Follow-up-Untersuchung bei 103 Frauen mit hc 2 und bei 41 Frauen mit RealTime ermittelt. Von einem Rezidiv bzw. einer persistierenden CIN wurde ausgegangen bei histologisch gesicherter CIN2+ oder vergleichbarem zytologischem Befund.

Ergebnisse Von 144 Frauen mit vollständigen Daten hatten 12 (8,3\%) ein Rezidiv nach Konisation. Eine HPV-Persistenz im Follow-up korrelierte signifikant mit einem Rezidiv (hc2: $p=0,003$ bzw. RealTime: $p=0,003$ ) bei hoher Sensitivität bzw. Spezifität (hc2 = 100 bzw. 78,4\%; RealTime = 75,0 bzw. 83,9\%). Während der positiv prädiktive Wert der alleinigen HPV-Testung für ein Rezidiv relativ niedrig lag (hc2 16\%; RealTime 54,5\%), stieg dieser bei HPV-16-Nachweis im Follow-up auf $80 \%$ an. 
Schlussfolgerung Im Follow-up nach Konisation einer CIN liefert eine Kombination aus Hochrisiko-HPV-Nachweis und partieller Genotypisierung von HPV 16 sehr gute Testgütekriterien für ein Rezidiv bzw. eine Persistenz der CIN.

\section{Introduction}

High-grade cervical intraepithelial neoplasia (CIN) and cervical carcinoma (CC) are associated with high-risk type human papilloma virus (hr-HPV) infection in over $99 \%$ of cases. The International Agency for Research on Cancer (IARC) classifies 12 (16, 18, 31, 33 , $35,39,45,51,52,56,58$ und 59) of the 150 HPV types as class one carcinogens. Genotypes 16 and 18 are among the most common worldwide and are found in over $70 \%$ of squamous cell carcinomas ( $85 \%$ of CC) and in over $80 \%$ of adenocarcinomas and adenosquamous carcinomas (15\% of CC) [1-4].

The precancerous lesions CIN and adenocarcinoma in situ (AIS) can be effectively treated with the various available surgical interventions and laser ablation (ectocervical CIN) [5-7]. Loop excision is the most commonly used method, which, in contrast to e.g. laser ablation, allows acquisition of a cone biopsy for histological analysis and assessment of endo- and ectocervical resection margins [8, 9].

Despite surgical intervention residual findings and recurrences occur in 5 to $25 \%$ of cases following conization of a CIN-3 lesion. This is attributed to non-in sano resection or persistent and newly acquired HPV infections [10].

For this reason the follow-up examination is essential and detection methods with high sensitivity and specificity for recurrence are required. The American Society for Colposcopy and Cervical Pathology (ASCCP) currently recommends combined cytology and HPV status testing (so-called co-testing) 12 and 24 months after conization for CIN 2+ [11]. According to the current German S3 guideline (consultation version) co-testing should be performed at 6, 12 and 24 months after conization. Should this co-testing be negative on all three occasions the return to routine screening is recommended. In the presence of co-testing positivity, however, differentiated colposcopy should be performed [12].

In recent decades the Hybrid Capture 2 HPV DNA Test (hc2; Qiagen, Hilden, Germany) was the most commonly used HPV test in clinical practice worldwide and in studies was most often the primary method for hr-HPV detection [13-15]. In addition, the hc2 is the standard against which new HPV test methods are measured; to be regarded as suitable tests non-inferiority to hc2 in terms of clinical sensitivity and specificity must be demonstrated $[15,16]$.

Such non-inferiority has been shown for the Abbott RealTime High Risk HPV Test (RealTime; Abbott, Wiesbaden, Germany), a PCR-based HPV detection method, in studies by Poljak et al. [17] and Carozzi et al. [18].

The aim of this retrospective study was to evaluate both abovementioned test methods with respect to prediction of CIN recurrence after conization. In this context, using RealTime, we tested the partial course of HPV 16 infection, i.e. persistence, in particular as a predictor of recurrence. We also considered the recurrence prediction potential of co-testing of cytology and course of HPV infection.

\section{Materials and Methods}

\section{Study population}

Between January 2007 and December 2013 a total of 717 patients underwent conization at the Department of Gynaecology and Obstetrics at the Hannover Medical School, mostly in the presence of known CIN, AIS or microinvasive cervical carcinoma (also see [19]). Most of these patients were examined preoperatively in the dysplasia clinic. Many were also referred for follow-up. At colposcopy a fresh cytology swab (mostly fluid cytology; ThinPrep, Hologic, Wiesbaden) in combination with an HPV test were always performed. In 2011 the hospital's HPV test changed from hc2 to RealTime, thus forming two patient groups for comparison with one another. Since this study aimed to test the validity of preand postoperative testing with the same HPV test method, 573 patients (79.9\%) could not be included ( $\vee$ Fig. 1 ).

\section{Data acquisition}

The data were collected from patient clinical histories, examination findings as well as from surgical and pathology reports. Cytology reporting was according to the Munich nomenclature II since this was valid until 12/2013. For this study the Bethesda classification was also applied with the formation of two groups ( $\leq$ low grade squamous intraepithelial lesions [ $\leq \mathrm{LSIL}$ ] or high grade squamous intraepithelial lesions [ $\geq \mathrm{HSIL}]$ ). Histology reporting was according to the CIN classification (CIN1-3, AIS, cervical carcinoma).

Persistence or recurrence was defined as histologically confirmed CIN2+ and/or cytology findings of $\geq \mathrm{HSIL}$ during followup, the higher grade results always being regarded as relevant. In cases with no histology results, where recurrence was suspected on cytology the documented clinical course was scrutinised to determine whether progressive higher grade dysplasia developed and if so, the case was classified as a recurrence. If not, and in the presence of normalised results, these initially suspicious cytology results were not regarded as recurrences.

HPV genotyping was performed using RealTime in 41 patients (28.5\%) and the remaining 103 patients $(71.5 \%)$ were tested for HPV positivity using hc 2 . The predictive power for recurrence of the three factors HPV status (hc2 vs. RealTime), HPV persistence (hc2 vs. RealTime) and partial HPV genotyping at follow-up was analysed by forming two cohorts in each case, each with applicable criteria. E. g. for HPV 16 persistence, only cases shown to be HPV 16 positive before conization and at follow-up approx. six months later were analysed. The test quality was then calculated for each cohort. 


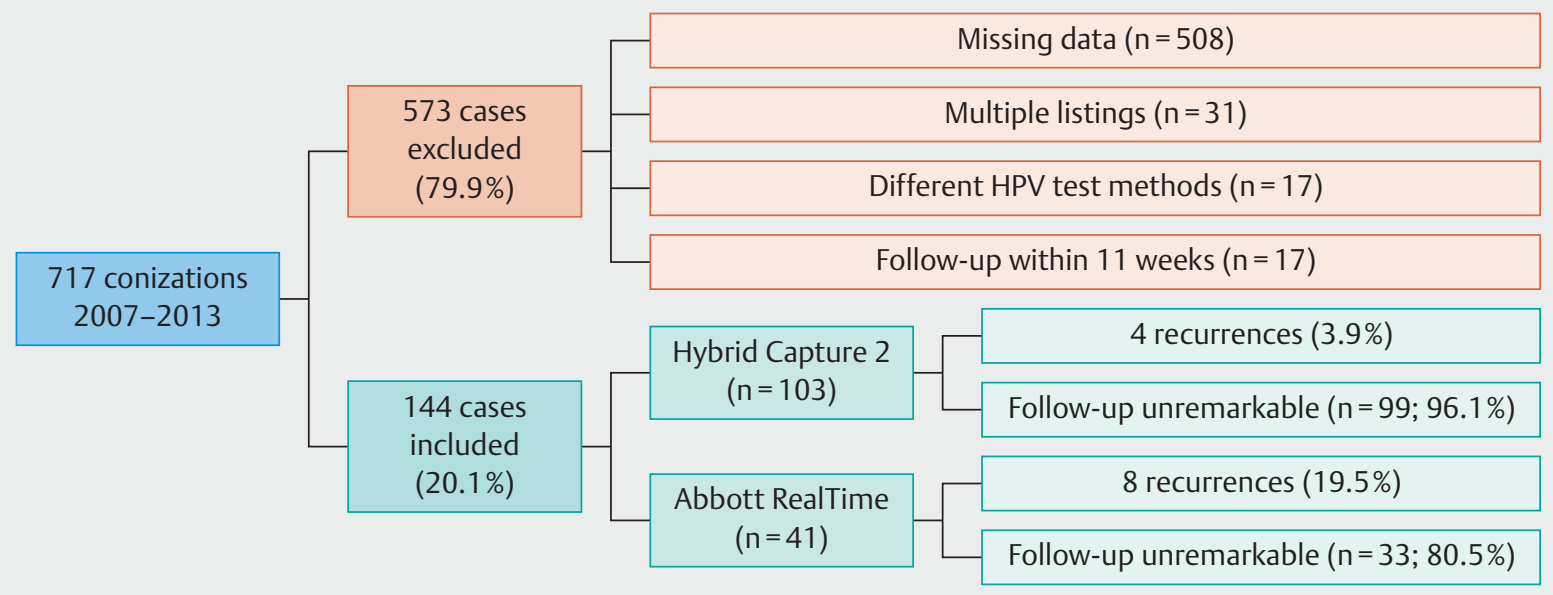

- Fig. 1 Study inclusions and exclusions.

\section{HPV test methods}

RealTime is a qualitative multiplex test based on real-time PCR used for the detection of $14 \mathrm{hr}-\mathrm{HPV}$ genotypes $(16,18,31,33$, $35,39,45,51,52,56,58,59,66$, and 68) with simultaneous genotyping of HPV type 16 and 18 . Hc2 is an in vitro nucleic acid hybridising assay for qualitative detection of $13 \mathrm{hr}-\mathrm{HPV}$ genotypes $(16,18,31,33,35,39,45,51,52,56,58,59$, and 68). The tests were performed according to the manufacturers recommendations (detailed description in [20]).

Apart from HPV status and cytology, cone height (categorisation according to Kliemann et al. [21]) and weight (categorisation into two similar sized subgroups), resection margins, endocervical re-resection, menopause status and the transformation zone were also analysed in terms of correlation with recurrence.

Data were collected and analysed using Excel version 2007 (Microsoft) and IBM SPSS Statistics 22 (IBM Corporation, Armonk, NY, USA). Significance testing was performed using Fisher's exact test and $p$-values of $<0.05$ were regarded as significant.

\section{Results}

\section{Patient data}

The average age of the 144 patients included in the study was $36.1 \pm 8.7$ years (range: $21.8-68.5$ ), $90.3 \%$ was premenopausal. Cone histology is shown in $>$ Table 1 . Both cases of invasive carcinoma were microinvasive carcinomas that were only diagnosed at conization. Both cases did not require further surgery and there was no evidence of recurrence at follow-up.

The first follow-up examination was performed after 6.4 months \pm 2.8 (range: $2.8-17.2$ ), 123 patients (85.4\%) having an "unremarkable result" (histology $\leq$ CIN 1 or cytology $\leq$ LSIL). In a further nine patients with only abnormal cytology at 1st followup recurrence was subsequently excluded so that overall 132 patients $(91.7 \%$ ) without recurrence were included in the analysis. In contrast a total of 12 patients were diagnosed with recurrence or
- Table 1 Cone histology.

\begin{tabular}{|l|r|r|r|}
\hline Histology (conization) & hc2 & RealTime & Total \\
\hline No dysplasia & 3 & 1 & 4 \\
\hline CIN1 & 8 & 3 & 11 \\
\hline CIN2 & 21 & 11 & 32 \\
\hline CIN3 & 69 & 23 & 92 \\
\hline AIS & 1 & 2 & 3 \\
\hline CC & 1 & 1 & 2 \\
\hline Total & 103 & 41 & 144 \\
\hline CIN: cervical intraepithelial neoplasia; AIS: adenocarcinoma in situ; \\
\hline CA: cervical carcinoma
\end{tabular}

persistence (8.3\%) defined as CIN2+ at 1st follow-up (7 patients, $4.9 \%$ ) and/or initial abnormal cytology ( $\geq$ HSIL) and subsequent histologically proven new high-grade dysplasia (5 patients, $3.5 \%)$. There were 4 recurrences in the hc2 group (4/103; 3.9\%) and 8 in the RealTime group (8/41; 19.5\%).

\section{Predictors of recurrence at first follow-up examination after conization}

140 patients (97.2\%) had positive HPV results preoperatively whereas, following surgical intervention, 36 women (25.0\%) still tested positive for HPV infection and 104 (72.2\%) tested negative. Four patients (2.8\%) were negative for HPV infection both preand postoperatively. Of the 41 patients $(28.5 \%)$ who were tested with RealTime pre- and postoperatively multiple infections were detected in 9 cases $(22.0 \%)$ ( $\triangleright$ Table 2$)$. Test quality criteria for the different HPV constellations are shown in ₹ Fig. 2 and Table 3.

HPV testing at first follow-up using RealTime produced false negative results in two cases with recurrence. In one of these cases the recurrence was primarily identified by pathological cytology only. CIN2 (p16 immunohistochemistry negative) was later 


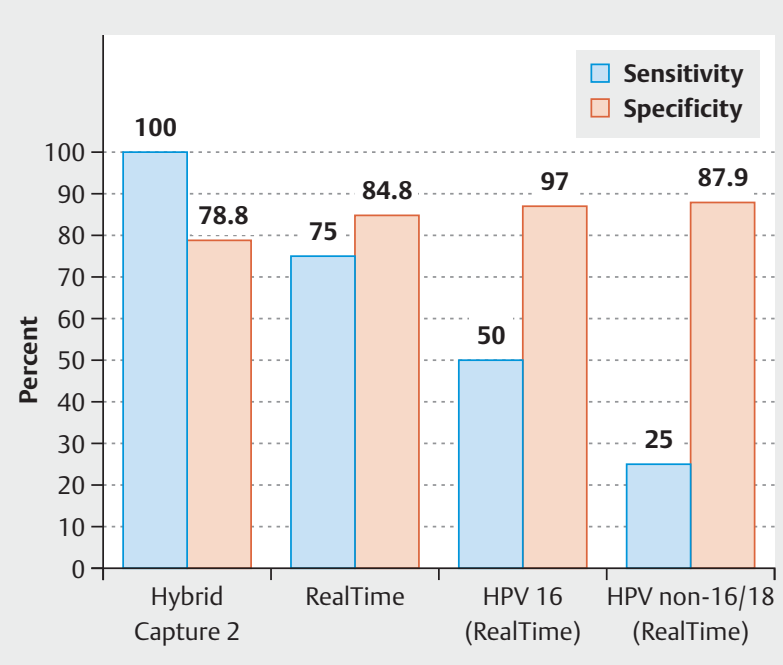

- Fig. 2 Sensitivity and specificity of postoperative HPV status for recurrence prediction, $n=144$, values in percent (\%).

confirmed. The second HPV negative recurrence was detected at follow-up and confirmed as AIS at biopsy after previous HPV positive CIN3.

Positive co-testing was defined as either positive HPV results, cytology results of $\geq$ LSIL or a combination of both parameters. Positive co-testing with both hc 2 + cytology and with RealTime + cytology correlated significantly with recurrence recognition ( Table 4).
- Table 2 The course of multiple HPV infections detected using RealTime $(n=41)$.

\begin{tabular}{|l|l|l|l|}
\hline HPV genotypes & Preoperative & Follow-up \\
\hline HPV 16 & 14 & 5 \\
\hline HPV 18 & & 1 & 0 \\
\hline HPV 18 & +16 & 1 & 0 \\
\hline HPV 18 & + non-16/18 & 1 & 0 \\
\hline non-16/18 & & 15 & 6 \\
\hline non-16/18 & +16 & 7 & 0 \\
\hline HPV negative & & 2 & 2 \\
\hline
\end{tabular}

Following conization cone heights of $<11 \mathrm{~mm},<13 \mathrm{~mm}$, $<20 \mathrm{~mm}$ and cone weight of $\leq 1 \mathrm{~g}$ did not correlate with increased recurrence risk when compared to larger or heavier cone biopsies (cone height $11 \mathrm{~mm}$ : $p=0.732 ; 13 \mathrm{~mm}: \mathrm{p}=1.000 ; 20 \mathrm{~mm}$ : $p=1.000$; cone weight $p=1.000$ ). The transformation zone, determined during preoperative testing and at follow-up, was also not significant for the prediction of recurrence (preoperative: $p=0.147$; follow-up: $p=0.702$ ).

In $65.3 \%$ of cases (94 patients) an endocervical re-resection was performed in addition to conization (7/94 recurrences; $7.4 \%)$, the remaining cases having conization alone (4/49 recurrences; $8.2 \%$ ). In this study re-resection was not shown to provide any additional benefit with respect to recurrence reduction $(p=1.000)$.

- Table 3 HPV test methods and recurrence prediction.

\begin{tabular}{|c|c|c|c|c|c|c|c|c|c|}
\hline Cohort & $\mathbf{n}$ & Recurrence & $\begin{array}{l}\text { Test } \\
\text { positive }\end{array}$ & $\begin{array}{l}\text { Test } \\
\text { negative }\end{array}$ & Sens. \% & Spec. \% & PPV \% & NPV \% & p-value \\
\hline \multirow[t]{2}{*}{ hc 2 status (1st follow-up) } & \multirow[t]{2}{*}{103} & yes & 4 & 0 & \multirow[t]{2}{*}{100} & \multirow[t]{2}{*}{78.8} & \multirow[t]{2}{*}{16} & \multirow[t]{2}{*}{100} & \multirow[t]{2}{*}{0.003} \\
\hline & & no & 21 & 78 & & & & & \\
\hline \multirow[t]{2}{*}{ RealTime status (1st follow-up) } & \multirow[t]{2}{*}{41} & yes & 6 & 2 & \multirow[t]{2}{*}{75} & \multirow[t]{2}{*}{84.8} & \multirow[t]{2}{*}{54.5} & \multirow[t]{2}{*}{93.3} & \multirow[t]{2}{*}{0.002} \\
\hline & & no & 5 & 28 & & & & & \\
\hline \multirow[t]{2}{*}{ hc2 persistence } & \multirow[t]{2}{*}{101} & yes & 4 & 0 & \multirow[t]{2}{*}{100} & \multirow[t]{2}{*}{78.4} & \multirow[t]{2}{*}{16} & \multirow[t]{2}{*}{100} & \multirow[t]{2}{*}{0.003} \\
\hline & & no & 21 & 76 & & & & & \\
\hline \multirow[t]{2}{*}{ RealTime persistence } & \multirow[t]{2}{*}{39} & yes & 6 & 2 & \multirow[t]{2}{*}{75} & \multirow[t]{2}{*}{83.9} & \multirow[t]{2}{*}{54.5} & \multirow[t]{2}{*}{92.9} & \multirow[t]{2}{*}{0.003} \\
\hline & & no & 5 & 26 & & & & & \\
\hline \multirow[t]{2}{*}{ HPV 16 status (1st follow-up) } & \multirow[t]{2}{*}{41} & yes & 4 & 4 & \multirow[t]{2}{*}{50} & \multirow[t]{2}{*}{97} & \multirow[t]{2}{*}{80} & \multirow[t]{2}{*}{88.9} & \multirow[t]{2}{*}{0.003} \\
\hline & & no & 1 & 32 & & & & & \\
\hline \multirow[t]{2}{*}{ HPV 16 persistence } & 22 & yes & 4 & 0 & 100 & 94.4 & 80 & 100 & 0.001 \\
\hline & & no & 1 & 17 & & & & & \\
\hline HPV non- $16 / 18$ status & 41 & yes & 2 & 6 & 25 & 87.9 & 33.3 & 82.9 & 0.578 \\
\hline (1st follow-up) & & no & 4 & 29 & & & & & \\
\hline HPV non- $16 / 18$ persistence & 23 & yes & 2 & 3 & 40 & 88.9 & 50 & 84.2 & 0.194 \\
\hline & & no & 2 & 16 & & & & & \\
\hline
\end{tabular}

n: number; hc2: Hybrid Capture 2 Assay; RealTime: Abbott RealTime Assay; PPV: positive predictive value; NPV: negative predictive value 
- Table 4 Co-testing methods and recurrence recognition.

\begin{tabular}{|c|c|c|c|c|c|c|c|c|c|}
\hline & $\mathbf{n}$ & Recurrence & $\begin{array}{l}\text { Test } \\
\text { positive }\end{array}$ & $\begin{array}{l}\text { Test } \\
\text { negative }\end{array}$ & Sens. $\%$ & Spec. \% & PPV \% & NPV \% & p-value \\
\hline \multirow[t]{2}{*}{ Cytology + hc2 } & \multirow[t]{2}{*}{103} & yes & 4 & 0 & \multirow[t]{2}{*}{100} & \multirow[t]{2}{*}{78.8} & \multirow[t]{2}{*}{16} & \multirow[t]{2}{*}{100} & \multirow[t]{2}{*}{0.003} \\
\hline & & no & 21 & 78 & & & & & \\
\hline \multirow[t]{2}{*}{ Cytology + RealTime } & \multirow[t]{2}{*}{41} & yes & 8 & 0 & \multirow[t]{2}{*}{100} & \multirow[t]{2}{*}{78.8} & \multirow[t]{2}{*}{53.3} & \multirow[t]{2}{*}{100} & \multirow[t]{2}{*}{$<0.001$} \\
\hline & & no & 7 & 26 & & & & & \\
\hline \multirow[t]{2}{*}{ Cytology + HPV 16 persistence } & \multirow[t]{2}{*}{22} & yes & 4 & 0 & \multirow[t]{2}{*}{100} & \multirow[t]{2}{*}{88.9} & \multirow[t]{2}{*}{66.7} & \multirow[t]{2}{*}{100} & \multirow[t]{2}{*}{0.002} \\
\hline & & no & 2 & 16 & & & & & \\
\hline
\end{tabular}

PPV: positive predictive value; NPV: negative predictive value; hc2: Hybrid Capture 2 Assay; RealTime: Abbott RealTime assay; HPV: human papilloma virus

The predictive value of cone biopsy resection margin status was also evaluated. 19 cases (13.2\%) were excluded due to uncertain results. R1 status, i.e. non-in sano resection, was present in 13 cases ( $9 \%)$. Five of these 13 patients $(38.5 \%)$ had a recurrence whereas six of the 112 patients (5.4\%) with R0 histology had a recurrence $(p=0.002 ; \triangleright$ Table 5).

\section{Discussion}

\section{HPV status}

Determination of HPV status forms part of the currently recommended standard follow-up after conization of high-grade cervical dysplasia (simple hr-HPV detection without genotyping) [11, 12]. The two test methods evaluated in our study, hc2 and RealTime, were shown to have clinical sensitivity and specificity of 100 and $78.8 \%$ (hc2)/specificity $84.8 \%$ for RealTime respectively. These are predictive values for recurrence that correlate well with other comparable studies (hc2: sensitivity 97.4\% [94.7-100\%], specificity $87.9 \%$ [83.3-92.6\%], RealTime: specificity $89.4 \%$ [86.4-92.3\%] [17, 18,22]). Similar to our findings these studies also found a tendency towards higher specificity for RealTime compared to hc2 and higher clinical sensitivity for hc 2 .

Our findings differ from the above-mentioned studies in terms of a lower sensitivity for RealTime (75.0 vs. 96.7\% [95.5-98.2\%]). 2/8 patients (25.0\%) with recurrence had negative RealTime HPV tests at follow-up. However with only eight cases of recurrence in the RealTime group this result is of limited validity. It is also questionable whether the two cases were indeed "actual recurrences". In one case CIN2 was diagnosed at follow-up that was negative for p16 on immunohistochemistry and was thus probably not caused by hr-HPV but possibly by low-risk HPV. In the second case with a negative RealTime HPV test the follow-up biopsy (after previous CIN3) confirmed AIS. Subsequent re-conization was however unremarkable/normal. Both cases were nevertheless treated as recurrences in view of the original inclusion criteria defined at the start of the study. Without these two cases the sensitivity of RealTime would also have been $100 \%$. A degree of selection bias can therefore not be excluded.

The significantly higher recurrence rate in the RealTime group (19.5\%; 8/41 cases) compared to the hc2 collective (3.9\%; 4/103
- Table 5 Resection margin status for prediction of recurrence.

\begin{tabular}{|l|c|c|c|c|}
\hline & R0 & R1 & Total & P-value \\
\hline No residual/recurrence & 106 & 8 & 114 & \\
\hline Residual/occurrence & 6 & 5 & 11 & 0.002 \\
\hline Total & 112 & 13 & 125 & \\
\hline Recurrence rate & $5.4 \%$ & $38.5 \%$ & $8.8 \%$ & \\
\hline PPV: positive predictive value; NPV: negative predictive value \\
\hline
\end{tabular}

cases) can also be explained by these two specific cases and to some extent also by the small total case number.

A further limitation of the study is the relatively small case number overall with different sized groups for testing with the two methods (hc2 103 patients, RealTime 41 patients). HPV 16 could thus only be evaluated in 22 patients. This is due to the fact that only patients tested preoperatively and at follow-up with the same HPV testing method were included.

A study by Kaliterna et al. [23] that included 108 patients - a similar sized study population to the 103 patients tested with hc2 in our study - found a similar sensitivity and specificity for this HPV test (Kaliterna: 88.2 and 79\% vs. hc2: 100 and 78,8\%).

Strand et al. in their study [24] note the potentially good predictive value of HPV genotyping for the presence of CIN2+ recurrence. In our study we evaluated the course of HPV infection using hc2 and RealTime. We initially pooled RealTime results according to HPV positivity or negativity without performing a genotype specific analysis. These results showed no recurrence prediction advantage in terms of sensitivity and specificity for the observation of the course of HPV infection using hc2 and RealTime (pooled) (hc2: sensitivity $100 \%$, specificity $78.4 \%$; RealTime: sensitivity $75.0 \%$, specificity $83.9 \%$ ) over determination of HPV status only at first follow-up after conization (hc2: sensitivity $100 \%$, specificity $78.8 \%$; RealTime: sensitivity $75.0 \%$, specificity $84.8 \%$ ) ( $\bullet$ Fig. 2).

This was also not to be expected, since for both test methods (pooled HPV status) the numbers of HPV persistence matched those of HPV positive results at 1st follow-up. Likewise the num- 
ber of HPV eradications corresponded to that of HPV negative results after conization.

\section{Genotyping}

RealTime enables the evaluation of the course of genotype specific infections with HPV 16 and 18. Independent of preoperative findings, exclusive testing of HPV 16 postoperatively had a sensitivity and specificity of 50.0 and $97.0 \%$ respectively for the detection of CIN2+. Testing for this specific HPV type achieved the highest specificity of all parameters assessed in this study (1st follow-up: HPV 16 97.0\%, hc2 78.8\%, RealTime - total 84.8\%, non$16 / 18 \mathrm{hr}-\mathrm{HPV} 87.9 \%)$. The specificity of HPV genotyping was also clearly higher than non-specific hr-HPV detection in a study by Heymans et al. [25].

We found a significantly lower sensitivity for CIN2+ at followup (50.0\%) with exclusive testing for HPV 16 (hc2 100\%, RealTime pooled $75.0 \%$ ). Reasons for this are again the above-mentioned two HPV negative recurrences and two cases with recurrence due to non-16/18 hr-HPV genotypes and negative HPV 16 results.

4/5 patients with HPV 16 persistence had a recurrence (PPV $80.0 \%$ ). This result is similar to those of a Norwegian study by Vintermyr et al. [26] in which $94.8 \%$ of patients with recurrence were shown to have persistent hr-HPV infection, of which $70.9 \%$ were genotypes 16/18. This study also described no change in HPV 16 prevalence before and after conization, a finding not confirmed by our study. Only five of the initial 22 positive patients (22.7\%) still tested positive for HPV 16 infection postoperatively ( $\vee$ Table 5 ).

These results confirm that partial HPV genotyping is a promising option. The PPV of $80 \%$ for HPV 16 persistence allows relatively reliable identification of women in imminent danger of recurrence. In contrast to this, the PPV of exclusive hc2 testing at follow-up is only around $16 \%$.

Exclusive use of non-16/18 hr-HPV genotypes for testing at first follow-up and diagnosis of persistence after conization are, with sensitivities of 25.0 and $40.0 \%$ respectively, not meaningful parameters for post-conization monitoring. It is possible that identification of type-specific persistence with certain non-16/18 hr-HPV genotypes could also have relatively high PPV. To answer this question, however, complete HPV genotyping would be required.

The postoperative status and course of HPV 18 infections could not be evaluated since only three patients were identified with this genotype preoperatively and in all three cases the virus was no longer detectable after conization.

\section{Co-testing}

Positive co-testing (positive HPV result and/or $\geq$ LSIL) with hc2 and cytology did not improve sensitivity and specificity compared to hc2 alone ( $n=103 ; 100$ and 78.8\%). The correlation between positive co-testing and the incidence of recurrence remained significant ( $p=0.003)$.

The combination of RealTime and cytology increased sensitivity to $100 \%$ for positive co-testing compared to HPV testing alone (75.0\%), specificity remaining almost unchanged ( $n=41 ; 78.8$ vs. $84.8 \%)$.

\section{Other parameters}

Cone height was not significant for recurrence prediction. Resection margins were clear $92.6 \%$ of the time at a cone height of $11 \mathrm{~mm}, 94.4 \%$ at $13 \mathrm{~mm}$ and $100 \%$ when cone height was $20 \mathrm{~mm}$. These results correspond to the findings of Kliemann et al. [21] (11 mm = 90\%, $13 \mathrm{~mm}=95 \%, 20 \mathrm{~mm}=100 \%)$.

Only a limited analysis of resection margins was possible in this study since involvement (R1) was pooled with no differentiation between endo- and ectocervical involvement. 6/112 patients (5.4\%) with R0 resection on histology had recurrences while 5/13 patients (38.5\%) with $R 1$ resections had recurrences $(p=0.002)$.

However Johnson et al. [27], in agreement with previous studies $[28,29]$, showed that only involvement of the endocervical resection margin can be regarded as predictive of recurrence.

Endocervical re-resection was not significant for the incidence of recurrence $(p=1.000)$. Of the 94 patients $(65.7 \%)$ who underwent re-resection 7 (7.4\%) had recurrence. Among the 49 patients (34.3\%) with no re-resection at conization 4 (8.2\%) had recurrence, a similar proportion to those who underwent re-resection. Our results support the supposition that endocervical re-resection and the associated additional shortening of the cervix can potentially be avoided.

\section{Conclusion}

Postoperative HPV status determined using the two test methods Hybrid Capture 2 and RealTime was shown to be highly specific for non-recurrence. Whereas the sensitivity of pooled HPV results for recurrence detection is very high, the PPV (16\%) of hc2 is extremely low. Here partial HPV genotyping has clear advantages. With a PPV of $80 \%$ recurrence should be expected especially in the context of (recurrent) detection of HPV 16 after conization. Thus the combination of pooled HPV testing (high sensitivity and NPV) and partial genotyping of HPV 16 (high PPV) can simplify follow-up management after conization.

Further prospective studies with systematic biopsy after conization are required for the further evaluation of the promising genotype specific monitoring of HPV 16 infection course and to compare this to pooled HPV testing.

\section{Conflict of Interest}

P. Hillemanns received research grants from GSK and Abbott as well as presentation remuneration from SPMSD, Roche and Hologic. $M$. Jentschke received presentation remuneration, travel and congress support from Abbott Molecular, Wiesbaden.

References

[1] Bosch FX, Burchell AN, Schiffman M et al. Epidemiology and natural history of human papillomavirus infections and type-specific implications in cervical neoplasia. Vaccine 2008; 26 (Suppl. 10): K1-K16

[2] Bouvard V, Baan R, Straif K et al. A review of human carcinogens-Part B: biological agents. Lancet Oncol 2009; 10: 321-322

[3] de Sanjose S, Quint WG, Alemany L et al. Human papillomavirus genotype attribution in invasive cervical cancer: a retrospective cross-sectional worldwide study. Lancet Oncol 2010; 11: 1048-1056 
[4] Walboomers JM, Jacobs MV, Manos MM et al. Human papillomavirus is a necessary cause of invasive cervical cancer worldwide. J Pathol 1999; 189: $12-19$

[5] Kalliala I, Nieminen P, Dyba T et al. Cancer free survival after CIN treatment: comparisons of treatment methods and histology. Gynecol Oncol 2007; 105: 228-233

[6] Kyrgiou M, Tsoumpou I, Vrekoussis T et al. The up-to-date evidence on colposcopy practice and treatment of cervical intraepithelial neoplasia: the Cochrane colposcopy \& cervical cytopathology collaborative group (C5 group) approach. Cancer Treat Rev 2006; 32: 516-523

[7] Nuovo J, Melnikow J, Willan AR et al. Treatment outcomes for squamous intraepithelial lesions. Int ] Gynaecol Obstet 2000; 68: 25-33

[8] Martin-Hirsch PP, Paraskevaidis E, Bryant A et al. Surgery for cervical intraepithelial neoplasia. Cochrane Database Syst Rev 2013; (12): CD001318

[9] Stasinou SM, Valasoulis G, Kyrgiou M et al. Large loop excision of the transformation zone and cervical intraepithelial neoplasia: a 22-year experience. Anticancer Res 2012; 32: 4141-4145

[10] Zielinski GD, Bais AG, Helmerhorst T] et al. HPV testing and monitoring of women after treatment of CIN 3: review of the literature and metaanalysis. Obstet Gynecol Surv 2004; 59: 543-553

[11] Massad LS, Einstein MH, Huh WK et al. 2012 updated consensus guidelines for the management of abnormal cervical cancer screening tests and cancer precursors. J Low Genit Tract Dis 2013; 17: S1-S27

[12] Leitlinienprogramm Onkologie (Deutsche Krebsgesellschaft DK, AWMF). Konsultationsfassung: Prävention des Zervixkarzinoms, Langversion. AWMF Registernummer: 015/027OL. 2016. Online: http://www. leitlinienprogramm-onkologie.de/leitlinien/zervixkarzinom-praevention; last access: 01.02.2017

[13] Cuzick J, Arbyn M, Sankaranarayanan R et al. Overview of human papillomavirus-based and other novel options for cervical cancer screening in developed and developing countries. Vaccine 2008; 26 (Suppl. 10): K29-K41

[14] Cuzick J, Clavel C, Petry KU et al. Overview of the European and North American studies on HPV testing in primary cervical cancer screening. Int J Cancer 2006; 119: 1095-1101

[15] Meijer C], Berkhof J, Castle PE et al. Guidelines for human papillomavirus DNA test requirements for primary cervical cancer screening in women 30 years and older. Int J Cancer 2009; 124: 516-520

[16] Arbyn M, Snijders PJ, Meijer C] et al. Which high-risk HPV assays fulfil criteria for use in primary cervical cancer screening? Clin Microbiol Infect 2015; 21: 817-826
[17] Poljak M, Ostrbenk A, Seme K et al. Comparison of clinical and analytical performance of the Abbott RealTime High Risk HPV Test to the performance of Hybrid Capture 2 in population-based cervical cancer screening. J Clin Microbiol 2011; 49: 1721-1729

[18] Carozzi FM, Burroni E, Bisanzi S et al. Comparison of clinical performance of Abbott RealTime High Risk HPV test with that of hybrid capture 2 assay in a screening setting. J Clin Microbiol 2011; 49: 1446-1451

[19] Müller K, Soergel P, Hillemanns P et al. Accuracy of colposcopically guided diagnostic methods for the detection of cervical intraepithelial neoplasia. Geburtsh Frauenheilk 2016; 76: 182-187

[20] Jentschke M, Soergel P, Lange V et al. Evaluation of a new multiplex realtime polymerase chain reaction assay for the detection of human papillomavirus infections in a referral population. Int J Gynecol Cancer 2012; 22: 1050-1056

[21] Kliemann LM, Silva M, Reinheimer M et al. Minimal cold knife conization height for high-grade cervical squamous intraepithelial lesion treatment. Eur J Obstet Gynecol Reprod Biol 2012; 165: 342-346

[22] Chung HS, Hahm C, Lee M. Comparison of the clinical performances of the AdvanSure HPV Screening Real-Time PCR, the Abbott Real-Time High-Risk HPV Test, and the Hybrid Capture High-Risk HPV DNA Test for Cervical Cancer Screening. J Virol Methods 2014; 205: 57-60

[23] Kaliterna V, Lepej SZ, Vince A. Comparison between the Abbott RealTime High Risk HPV assay and the Hybrid Capture 2 assay for detecting high-risk human papillomavirus DNA in cervical specimens. J Med Microbiol 2009; 58: 1662-1663

[24] Soderlund-Strand A, Kjellberg L, Dillner J. Human papillomavirus typespecific persistence and recurrence after treatment for cervical dysplasia. J Med Virol 2014; 86: 634-641

[25] Heymans ], Benoy IH, Poppe W et al. Type-specific HPV geno-typing improves detection of recurrent high-grade cervical neoplasia after conisation. Int J Cancer 2011; 129: 903-909

[26] Vintermyr OK, Iversen O, Thoresen S et al. Recurrent high-grade cervica lesion after primary conization is associated with persistent human papillomavirus infection in Norway. Gynecol Oncol 2014; 133: 159-166

[27] Johnson N, Khalili M, Hirschowitz L et al. Predicting residual disease after excision of cervical dysplasia. BJOG 2003; 110: 952-955

[28] Baldauf J], Dreyfus M, Ritter ] et al. Risk of cervical stenosis after large loop excision or laser conization. Obstet Gynecol 1996; 88: 933-938

[29] Flannelly G, Bolger B, Fawzi H et al. Follow up after LLETZ: could schedules be modified according to risk of recurrence? BJOG 2001; 108: 10251030 